\title{
First investigations on stoichiometric lithium niobate as piezoelectric substrate for high-temperature surface acoustic waves applications
}

\author{
Thierry Aubert, Ninel Kokanyan, Hassan Alhousseini, \\ Amine Taguett, Florian Bartoli \\ Laboratoire LMOPS EA 4423 \\ Université de Lorraine-CentraleSupélec \\ 57070 METZ, France \\ thierry.aubert@centralesupelec.fr
}

\author{
Jérémy Streque, Hamid M'Jahed, Pascal Boulet, Omar \\ Elmazria \\ Institut Jean Lamour UMR 7198 \\ UMR 7198 Université de Lorraine-CNRS \\ 54506 Vandœuvre-lès-Nancy, France
}

\begin{abstract}
Surface acoustic waves (SAW) technology is very promising to achieve high-temperature wireless sensors. However, there is currently a need for piezoelectric substrates with a high electromechanical coupling coefficient $\left(\mathrm{K}^{2}>1 \%\right)$, able to operate under harsh environments, especially in the intermediate temperature range $\left(300-600^{\circ} \mathrm{C}\right)$. None of the conventional SAW substrate can face this challenge. In particular congruent lithium niobate, whose $K^{2}$ can exceed $5 \%$, shows serious limitations from $300^{\circ} \mathrm{C}$, mainly related to $\mathrm{Li}$ vacancies. Recent studies have demonstrated the potential of stoichiometric lithium niobate (s-LN) for high-temperature bulk acoustic waves applications. In this paper, we investigate this piezoelectric material for high-temperature SAW applications. In particular, we examine carefully the potential structural and chemical changes that s-LN surface can undergo during a high-temperature exposure. Finally, SAW resonators based on s-LN substrates are in situ characterized up to $600^{\circ} \mathrm{C}$.
\end{abstract} $S A W$

Keywords—high-temperature; stoichiometric lithium niobate;

\section{INTRODUCTION}

Surface acoustic waves (SAW) technology has been being used for more than three decades for telecommunication applications. It is also of great interest for sensor applications owing to the potential large sensitivity of SAW devices to environmental conditions. Moreover, SAW sensors have a great added value as they are passive components. Consequently, they do need neither embedded electronics nor power source to be remotely interrogated. This property makes this technology particularly suitable to achieve wireless sensors able to operate in high-temperature environments $\left(200-1000^{\circ} \mathrm{C}\right)$, provided the constitutive materials of the device are able to withstand these harsh conditions.

In this context, conventional SAW piezoelectric substrates have limitations that prevent their use above some typical temperatures. For instance, quartz shows a $\alpha-\beta$ phase transition at $573^{\circ} \mathrm{C}$, but signal degradation occurs from $300^{\circ} \mathrm{C}$, likely due to the increase in structural disorder with temperature [1]. In the same way, it is preferable not to operate lithium tantalate and lithium niobate (LN) about half their Curie temperature, located at $610^{\circ} \mathrm{C}$ and $1140^{\circ} \mathrm{C}$ respectively [2]. Thus, congruent lithium niobate (c-LN) could be potentially used up to temperatures around $600^{\circ} \mathrm{C}$, allowing SAW measurements in the intermediate temperature range (ITR), between 300 and $600^{\circ} \mathrm{C}$. However, c-LN shows several limitations under high-temperature environments. First of all, as many oxides, LN is not stable under high-temperature poor-oxygen environments, undergoing strong $\mathrm{O}$ losses [3]. Moreover, owing to a significant concentration in $\mathrm{Li}$ vacancies, c-LN conductivity increases quickly with temperature [4]. Finally, the electrodes of SAW devices based on c-LN undergo important damages due to sparks related to $\mathrm{LN}$ pyroelectricity. Consequently, c-LN seems limited to applications up to $300^{\circ} \mathrm{C}$ [5].

Some other piezoelectric materials have been subsequently investigated in order to achieve high-temperature SAW devices. Langasite $\left(\mathrm{La}_{3} \mathrm{Ga}_{5} \mathrm{SiO}_{14}, \mathrm{LGS}\right)$ crystals have been intensively studied and have given promising results, especially under air environment. Thus LGS crystals surface do not deteriorate up to $1000^{\circ} \mathrm{C}$ [6] and remains piezoelectric up to at least $1140^{\circ} \mathrm{C}$ [7]. LGS-based SAW devices have been operated for several months at $800^{\circ} \mathrm{C}$ [8]. Other notable performances have been obtained with AlN/Sapphire bilayer structure. AlN suffers from steady oxidation above $700^{\circ} \mathrm{C}$ in air [9], but can be operated up to at least $1000^{\circ} \mathrm{C}$ under low-O environments [10] or in air if protected by an overlayer [11].

However, LGS as well as AlN/Sapphire are limited by relatively weak electromechanical coupling coefficients $\mathrm{K}^{2}$, which are not larger than $0.3 \%$. In particular, such $\mathrm{K}^{2}$ values prevent the achievement of reflective delay lines. The latter device geometry is very convenient for sensor identification, allowing the design of ID tags. Such design requires very short pulses in time domain, and thus wide passband in frequency domain, meaning a $\mathrm{K}^{2}$ typically above $1 \%$.

Thus, there is a need for a piezoelectric material with a high $\mathrm{K}^{2}$, able to withstand high-temperature environments, in particular in the ITR. One promising candidate could be 
stoichiometric lithium niobate (s-LN). This crystal presents much less defects of the lattice comparing to c-LN. The composition of a given LN crystal can be defined by the parameter $\mathrm{X}_{\mathrm{c}}$ (where $\mathrm{c}_{\mathrm{Li}}$ and $\mathrm{c}_{\mathrm{Nb}}$ are the concentrations in $\mathrm{Li}$ and $\mathrm{Nb}$ atoms in the crystal respectively):

$$
X_{C}=\frac{c_{L i}}{c_{L i}+c_{N b}} \cdot 100
$$

In s-LN crystals with ideal structure, $\mathrm{X}_{\mathrm{c}}$ is equal to $50 \%$, unlike to c-LN in which it is only of $48.3 \%$. It has to be noted that the growth of s-LN crystals is connected with some difficulties with comparison to the growth of the c-LN [12]. Due to less Li vacancies, the s-LN conductivity is much lower than that of c-LN, and thus very promising measurements of BAW devices based on s-LN have been recently achieved up to $900^{\circ} \mathrm{C}$ [13]. In this paper, we investigate the stability of the surface of s-LN crystals exposed to high temperatures up to $700^{\circ} \mathrm{C}$. Additionally, SAW devices based on s-LN crystals are electrically characterized up to $600^{\circ} \mathrm{C}$ by in situ measurements.

\section{EXPERIMENTAL}

Near stoichiometric Z-oriented LN wafers (MTI Corp., Richmond, CA) were cut into $20 \times 15 \mathrm{~mm}^{2}$ rectangular plates. Three samples were annealed in an open-air furnace for $12 \mathrm{~h}$ at $500^{\circ} \mathrm{C}, 600^{\circ} \mathrm{C}$ and $700^{\circ} \mathrm{C}$ respectively.

The chemical composition of the samples was obtained before and after annealing treatment by Raman spectroscopy measurements. Raman measurements were carried out with a Horiba Jobin Yvon ARAMIS spectrometer with a spectral resolution less than $1 \mathrm{~cm}^{-1}$. The He-Ne laser with $632.8 \mathrm{~nm}$ of wavelength was operated. The penetration depth was about $1 \mu \mathrm{m}$. The spectra of $\mathrm{Z}(\mathrm{XY}) \mathrm{Z}$ configuration were measured in order to obtain $\mathrm{E}[\mathrm{TO}]$ modes according to selection rules. The attention was focalized on E[TO1] Raman mode, corresponding to out of phase motion of $\mathrm{Nb}$ and $\mathrm{O}$ ions [14], which provides a possibility to calculate the composition of the crystal from the linewidth $\Gamma$ of this mode [15]:

$$
\mathrm{X}_{\mathrm{c}}=51.28-0.232 * \Gamma
$$

A fourth sample was structurally investigated by in situ X-ray diffraction (XRD) measurements performed with a D8 diffractometer (Bruker AXS, Karlsruhe, Germany) used in Bragg-Brentano geometry, equipped with a lynxeye PSD detector and using the CoK a radiation ( $\lambda=0.179026 \mathrm{~nm})$. These measurements were conducted between the ambient and $700^{\circ} \mathrm{C}$. Namely, the sample was rapidly heated from the ambient to $400^{\circ} \mathrm{C}$ and then maintained at this temperature for 12h. During this plateau, four XRD diagrams were obtained every $3 \mathrm{~h}$. The same procedure was repeated at 500, 600 and $700^{\circ} \mathrm{C}$. Finally, three last XRD diagrams were measured during the cooling phase at 600,500 and $400^{\circ} \mathrm{C}$ respectively.

150 -nm thick aluminum thin films were deposited on some others samples by sputtering method. SAW resonators with a wavelength of $6.5 \mu \mathrm{m}$ were then achieved by conventional photolithography and wet etching. The SAW propagation path was along $\mathrm{Y}$ direction. These devices were in situ electrically characterized up to $600^{\circ} \mathrm{C}$ using a network analyzer and an RF prober station (s-1160, Signatone Corp., Gilroy, CA) equipped with an S-1060 series Signatone thermal probing system. In order to allow a calibrated characterization of the devices, an adapted RF probes ( $Z$ Probe SussMicrotech) with cooling system was used.

\section{RESULTS AND DISCUSSIONS}

\section{A. Raman measurements}

The Raman measurements performed before annealing treatments show that the samples under consideration have a composition close to the stoichiometric one with the parameter $\mathrm{X}_{\mathrm{C}}$ being about $49.85 \%$. No noticeable changes of $\mathrm{E}\left[\mathrm{TO}_{1}\right]$ mode were observed for the same samples after the annealing processes at temperatures from 500 to $700^{\circ} \mathrm{C}$ (Fig. 1).

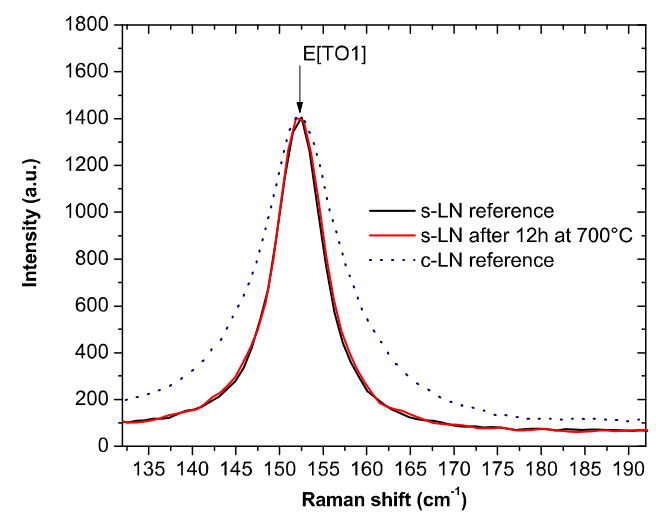

Fig. 1. $\mathrm{E}\left[\mathrm{TO}_{1}\right]$ mode of s-LN wafers before and after a $12 \mathrm{~h}$-long annealing process at $700^{\circ} \mathrm{C}$. $\mathrm{E}\left[\mathrm{TO}_{1}\right]$ mode of c-LN sample was added for comparison.

This result evidences that the chemical composition of the surface of the investigated s-LN crystals is not altered by the annealing treatments, the parameter $X_{c}$ staying in the range between 49.8 and $49.9 \%$.

\section{$B$. In situ XRD measurements}

The XRD diagram of the non-annealed samples contains only peaks corresponding to the $(00 l)$ reticular plans. No new phase appears during the $48 \mathrm{~h}$-long annealing process between 400 and $700^{\circ} \mathrm{C}$. This intensity of the main peak, corresponding to the (006) reflex, decreases with the temperature, in particular at $700^{\circ} \mathrm{C}$ (Fig. 2). However, this intensity remains constant during each $12 \mathrm{~h}$-long plateau, at $400,500,600$ and $700^{\circ} \mathrm{C}$ respectively (Fig. 3).

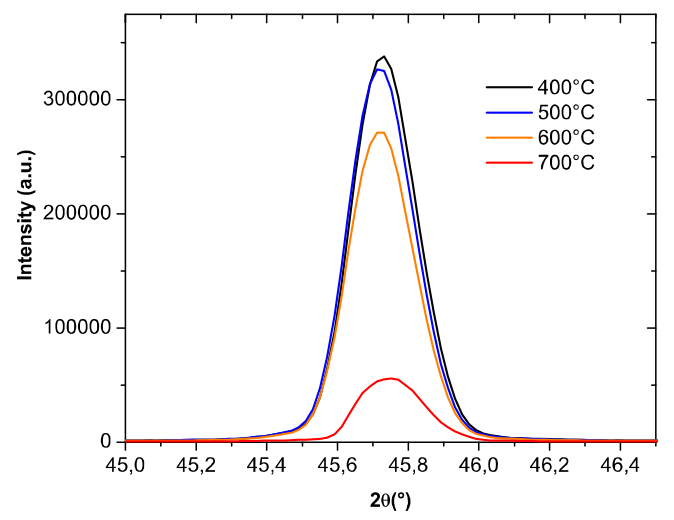

Fig. 2. s-LN (006) reflex measured at different temperatures 


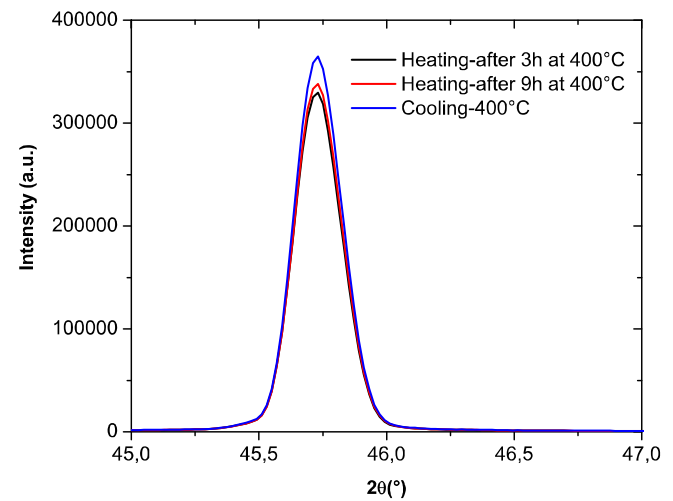

Fig. 3. s-LN (006) reflex measured at $400^{\circ} \mathrm{C}$ at different times

Moreover, the intensity measured during the cooling phase for each temperature of measurements is the same as during the heating phase plateaus (Fig. 3). Consequently, we can assume that the decrease of the XRD intensity with temperature is related to the Debye-Waller effect and not to a degradation of the crystal.

\section{In situ SAW measurements}

The devices were first electrically characterized by step of $25^{\circ} \mathrm{C}$ between the ambient and $600^{\circ} \mathrm{C}$. Then, they were steadily cooled back to room temperature and measured every $50^{\circ} \mathrm{C}$. During the heating phase, the quality factor degrades in the temperature range between 250 and $450^{\circ} \mathrm{C}$, and then improves back suddenly at $500^{\circ} \mathrm{C}$ (not shown here). The behavior is completely different during the cooling phase (Fig. 4). This time, the signal quality remains quite good in the temperature range between 500 and $300^{\circ} \mathrm{C}$, and then degrades significantly, except around $50^{\circ} \mathrm{C}$. These phenomena are not currently understood, and more investigations are required.

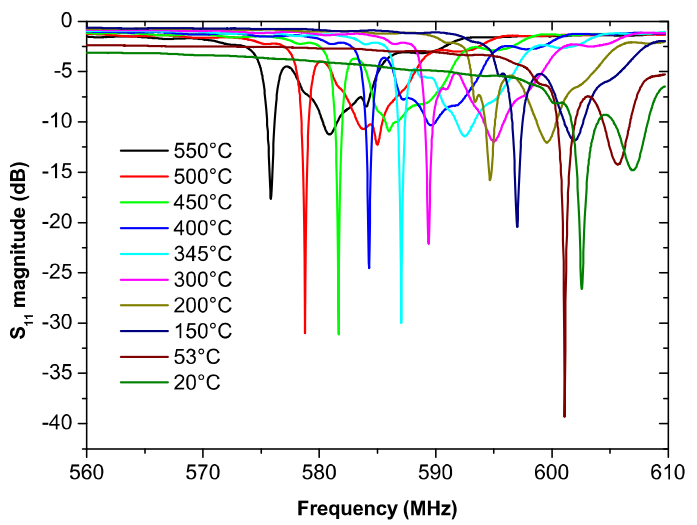

Fig. 4. $\mathrm{S}_{11}$ magnitude of s-LN-based SAW resonator characterized at different temperatures

\section{CONCLUSION AND PERSPECTIVES}

In situ XRD and Raman spectroscopy measurements show that the microstructure and the chemical composition of s-LN substrates are not altered by an exposure of several hours at high temperatures up to $700^{\circ} \mathrm{C}$. High-temperature characterization of sLN-based SAW resonators have been achieved up to $600^{\circ} \mathrm{C}$. Results are quite different between the heating and the cooling phase, possibly indicating the need for a pre-aging process. Additional experiments are ongoing to clarify this point.

\section{ACKNOWLEDGMENT}

This work was financially supported by the Lorraine Regional Council and the French PIA project "Lorraine Université d'Excellence", reference ANR-15-IDEX-04-LUE. Experiments were carried out on equipments part of IJL-TUBE Davm funded by FEDER (EU), PIA, region Grand Est, Metropole Grand Nancy and ICEEL.

\section{References}

[1] J. Haines, O. Cambon, D.A. Keen, M.G. Tucker, M.T. Dove, "Structural disorder and loss of piezoelectric properties in $\alpha$-quartz at high temperature," Appl. Phys. Lett., 81, no. 16, pp. 2968-2970, 2002.

[2] R. Turner, P. Fuierer, R. Newnham, T. Shrout, "Materials for high temperature acoustic and vibration sensors: a review," Applied Acoustics, 41, no. 4, pp. 299-324, 1994.

[3] M. Budimir, A. Mohimi, C. Selcuk, T. Gan, "High temperature NDE Transducers for Condition Monitoring of Superheated Steam Pipes in Nuclear Power Plants," in Proc. Internationel Conf. Nucl. Energy for New Europe, pp. 502.1-502.8, 2011.

[4] Y. Li, Y. Zheng, X. Tu, K. Xiong, Q. Lin, E. Shi, "High temperature resistivity of lithium niobate and related crystals," in Proc IEEE SPAWDA, pp. 283-286, 2014.

[5] R. Hauser, L. Reindl, J. Biniasch, "High temperature stability of $\mathrm{LiNbO}_{3}$ based SAW devices," in Proc IEEE Ultrasonics Symp., pp.192-195, 2003.

[6] T. Aubert and O. Elmazria, "Stability of langasite regarding SAW applications above $800^{\circ} \mathrm{C}$ in air atmosphere," in Proc. IEEE Ultrasonics Symp., pp. 2098-2101, 2012.

[7] T. Aubert, J. Bardong, O. Elmazria, G. Bruckner, B. Assouar, "Iridium interdigital transducers for high-temperature surface acoustic wave applications," IEEE Trans. Ultrason. Ferroelectr. Freq. Control, 59, no. 2, pp. 194-197, 2012.

[8] M. Pereira da Cunha, R. J. Lad, T. Moonlight, G. Bernhardt, D.J. Frankel, "High temperature stability of langasite surface acoustic wave devices," in Proc. IEEE Ultrasonics Symp., pp. 205-208, 2008.

[9] T. Aubert, O. Elmazria, B. Assouar, E. Blampain, A. Hamdan, D. Genève, S. Weber, "Investigations on AlN/sapphire piezoelectric bilayer structure for high-temperature SAW applications," IEEE Trans. Ultrason. Ferroelectr. Freq. Control, 59, no. 5, pp. 999-1005, 2012.

[10] T. Aubert, J. Bardong, O. Legrani, O. Elmazria, B. Assouar, G. Bruckner, A. Talbi, "In situ high-temperature characterization of AlNbased surface acoustic wave devices," J. Appl. Phys., 114, art. no. 014505, 2013.

[11] O. Legrani, T. Aubert, O. Elmazria, A. Bartasyte, P. Nicolay, A. Talbi, P. Boulet, J. Ghanbaja, D. Mangin, "AlN/IDT/AIN/Sapphire SAW heterostructure for high-temperature applications," IEEE Trans. Ultrason. Ferroelectr. Freq. Control, 63, pp. 898-906, 2016.

[12] T. Volk and M. Wohlecke, "Lithium Niobate: Defects, Photorefracion, and Ferroelectric Switching," Springer, Berlin, 264, 2008.

[13] A. Weidenfelder, J. Shi, P. Fielitz, G. Borchardt, K.D. Becker, H. Fritze, "Electrical and electromechanical properties of stoichiometric lithium niobate at high-temperatures," Solid State Ionics, 225, pp. 26-29, 2012.

[14] A.V. Postnikov, V. Caviuc, G. Borstel, "Structure optimization and frozen phonons in $\mathrm{LiNbO}_{3}$," J. Phys. Chem. Solids, 61, pp. 295, 2000.

[15] Y. Zhang, L. Guilbert, P. Bourson, K. Polgar, M. D. Fontana, "Caracterisation of short-range heterogeneities in sub-congruent lithium niobate by micro-Raman spectroscopy," J. Phys.: Condens. Matter, 18, pp. 957-963, 2006. 